IRA-International Journal of Management \& Social Sciences

ISSN 2455-2267; Vol.04, Issue 01 (2016)

Institute of Research Advances

http://research-advances.org/index.php/RAJMSS

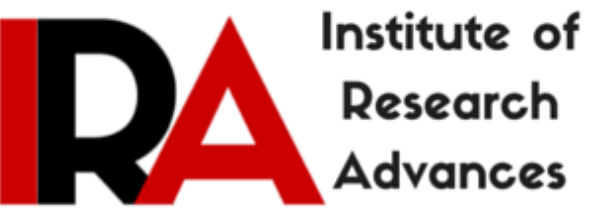

\title{
Profiling of the candidates: A Study of Recruitment and Selection Practices in A\&B Technology Services
}

\author{
Chandrakanta Sahoo \\ Assistant Professor \\ Department of Management Studies \\ Madanapalle Institute of Technology and Science, India.
}

DOI: http://dx.doi.org/10.21013/jmss.v4.n1.p19

\section{How to cite this paper:}

Sahoo, C. (2016). Profiling of the candidates: A Study of Recruitment and Selection Practices in A\&B Technology Services. IRA-International Journal of Management \& Social Sciences (ISSN 2455-2267), 4(1). doi:http://dx.doi.org/10.21013/jmss.v4.n1.p19

(C) Institute of Research Advances

\section{(cc) EY-No}

This works is licensed under a Creative Commons Attribution-Non Commercial 4.0 International License subject to proper citation to the publication source of the work.

Disclaimer: The scholarly papers as reviewed and published by the Institute of Research Advances (IRA) are the views and opinions of their respective authors and are not the views or opinions of the IRA. The IRA disclaims of any harm or loss caused due to the published content to any party. 


ABSTRACT
The present research paper discussed the recruitment and selection practices of A \& B Technology
Services (the name of the company is disguised for competitive and commercial reasons). The
company has a HR policy of recruiting candidates both from internal sources. But the research work
focuses on the profiling of candidates through external source only. The technique is used for
candidate profiling is yield ratio. Since, it's technology service company, it recruits technocrats
having expertize in software. The candidates' resumes are sourced from the job portals like Naukri,
Monster, Linkedin etc. processes through different phases up-to the final selection.

Key Words: Recruitment, Profiling, Yield-Ratio, Technology

\section{A \& B Limited:}

A \& B Limited is an Indian multinational conglomerate headquartered in Mumbai, India. Founded in 1938, the company has business interests in engineering, construction, manufacturing goods, information technology and financial services, and also has an office in the Middle East and other parts of Asia.

The organizational structure is of $\mathrm{H}$ - Structure (Holding or conglomerate structure). More than seven decades of a strong, customer-focused approach and the continuous quest for world-class quality have enabled it to attain and sustain leadership in all its major lines of business. It has an international presence, with a global spread of offices. A thrust on international business has seen overseas earnings grow significantly. It continues to grow its global footprint, with offices and manufacturing facilities in multiple countries. The company's businesses are supported by a wide marketing and distribution network and have established a reputation for strong customer support. It has delivered Engineering, Procurement and Construction (EPC) services for many projects in the upstream hydrocarbon sector over the last two decades, in India, Middle East, Africa, South-East Asia and Australia.

\section{A \& B Infotech}

A \& B Infotech is one of the wings of the Parent organization which focuses on information technology and software services. It is a 100 per cent subsidiary of the parent company and offers software and services with a focus on Manufacturing, BFSI and Communications and Embedded Systems. It also provides services in the embedded intelligence and engineering space.

Though it is a technology services company, it has not outsourced its recruitment function. It has a HR department which has been recruiting manpower for its requirement with the support of different departments' heads.

\section{Man power Profile}

The company looks for 4 categories employees which are put under 4 clusters.

\section{Table 1: Cluster 1}

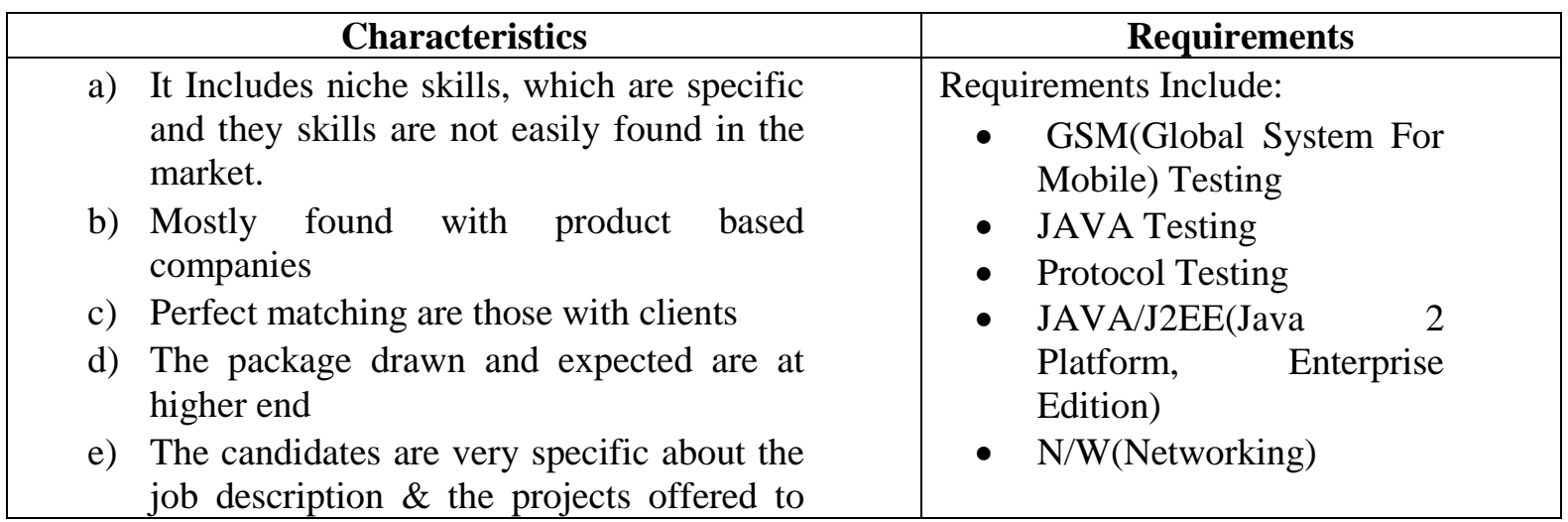




\begin{tabular}{|l|l|}
\hline them & Development \\
Most of them are interested in working & \\
with only product based companies & \\
g) Skill specific match is given importance & \\
by the managers. & \\
\hline
\end{tabular}

\section{Table 2: Cluster 2}

1) Available in abundant.

2) Not restricted to any organization.

3) They candidates mostly seems to work on broader skills, not on focused areas.

4) Domain specific experience is an added value.

5) Mostly candidates not ready to relocate.

6) Salary expectations can be met.

7) Avoid profiles from product based company as the CTC expected is high.

8) Mangers are very keen in getting in the profiles with least CTC expectations.

Table 3: Cluster 3

\begin{tabular}{l|l|}
\hline \multicolumn{1}{|c|}{ Characteristics } & \multicolumn{1}{|c|}{ Requirements } \\
\hline 1) Most profiles in the trending technologies/ & ENS/NMS \\
newer version found & - EPC \\
2) Candidates unwilling to work in the older & - N/W Testing \\
version & \\
3) Profiles matching, lack of communication & \\
4) Most of the candidates who are technically \\
average are rejected due to poor communication. \\
5) Salary expectation fit
\end{tabular}

Table 4: Cluster 4

\begin{tabular}{|l|ll|}
\hline \multicolumn{1}{|c|}{ Characteristics } & \multicolumn{2}{|c|}{ Requirements } \\
\hline 1) Unavailable or rarely available in market & $\bullet$ BO/BT/WIFI \\
2) High salary expectations & $\bullet$ LTE(Long Term \\
$\begin{array}{l}\text { 3) Managers after trying for exact match, ask for } \\
\text { similar profiles }\end{array}$ & $\bullet$ Evaluation) \\
\hline
\end{tabular}

\section{Recruitment Process}

Recruitment is a process of attracting the best-qualified candidate (from within or outside of an organization) for a job opening, in a timely and cost effective manner. The recruitment process includes analyzing the requirements of a job, attracting employees to that job, screening and selecting applicants, hiring, and integrating the new employee to the organization.

The company looks for the candidates from various job portals such as, Naukri, Monster, Times Job etc. After collecting the profile of the candidates, the recruiters compare the profile of the candidates with the job description to check whether the profile matches with the job requirements or not. This is the first round of the screening where candidates' profiles are filtered with the job requirement. The selected profiles are sent to the technical teams who further examine the suitability of the candidatures 
for the jobs. After proper examination, they sent back the selected profiles to the recruiters for scheduling the first round of interview which is telephonic in nature. Candidates selected at this round have to appeared for a web discussion using google handouts or Skype. This is followed by vis-à-vis interview by the technical team and finally by HR. The candidates who clear all these rounds are given job offers subject to the requirements. Candidates may accept or reject the offer and those who accept finally join the organization.

Table 5: Recruitment and Selection Process of A\&B Infotech

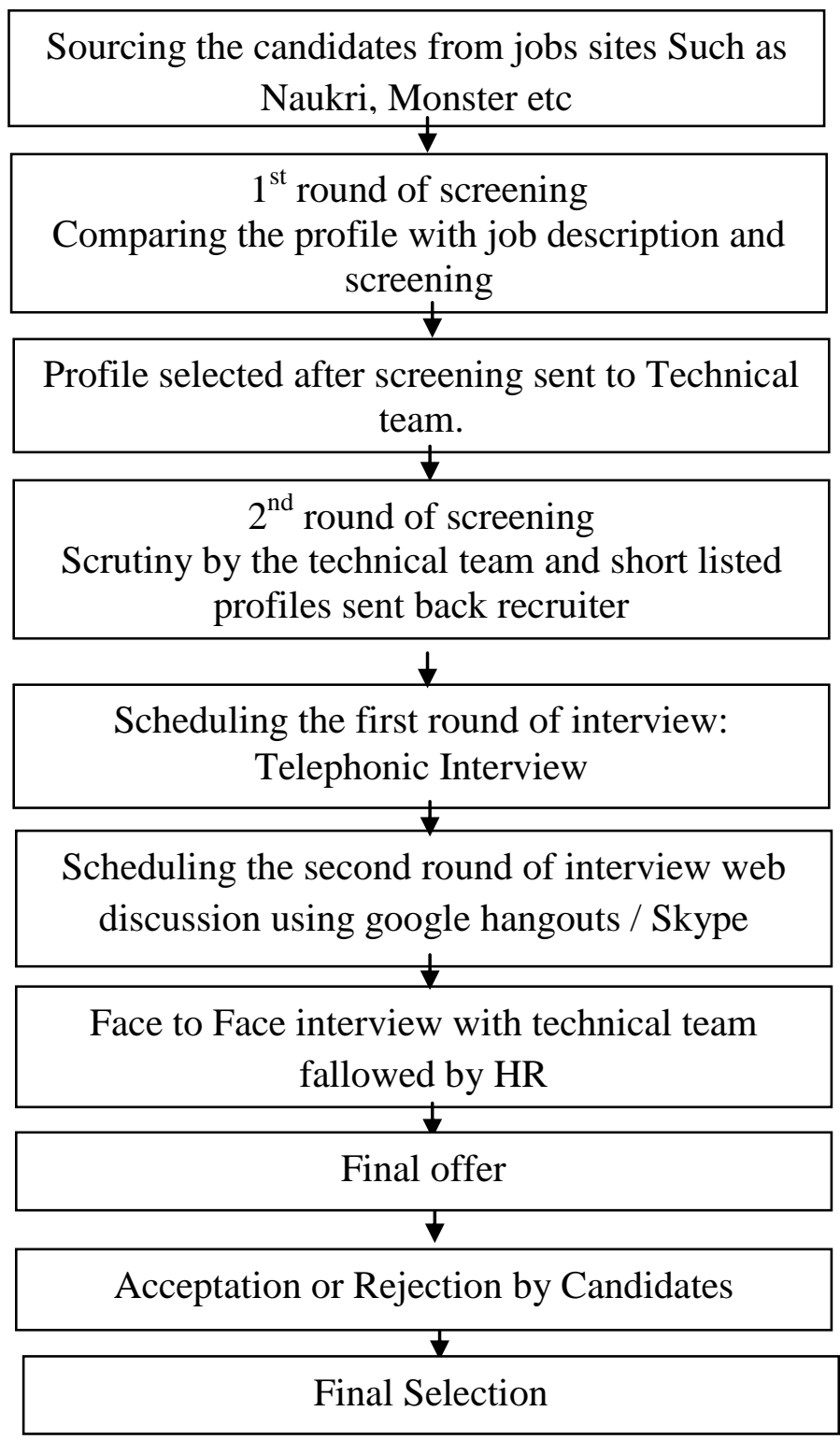

4.1. Recruitment Yield Ratio: Recruitment yield measures the success of recruitment strategies. Recruitment yield ratios refer to, for example, the ratio of candidates' resumes forwarded by the recruitment agency to those then shortlisted for interview those interviewed to offered, those offered to placed, across a business over time. 


\subsection{Profiling Candidates}

Profiling is the process of finding resumes within the recruitment process. Recruiters, both third party and corporate, need to find qualified candidates for their open job orders, oftentimes with very unique or niche work experience. Sourcing refers to the initial part of recruiting (actually finding the candidates through a variety of methods.) Some recruiters perform the sourcing function through to placement; other recruiting professionals specialize in only one aspect of the recruitment cycle. Professional recruiters who specialize only in the initial procurement of names and candidates are called sourcers. Many larger companies and specialist staffing firms employ teams of sourcing professionals that concentrate only on the initial procurement of candidates. The sourcers then "hand off" the candidates to a different department of team of recruiters which handle qualification, interview, and placement

\subsection{Recruitment policies}

1) In $A \& B$ technology services they are two types of recruitment process internal and external.

2) In the company, two times they took to computing requirement

- General Requirement

- Urgent Requirement

\subsection{Method of Calculating Yield Ratio:}

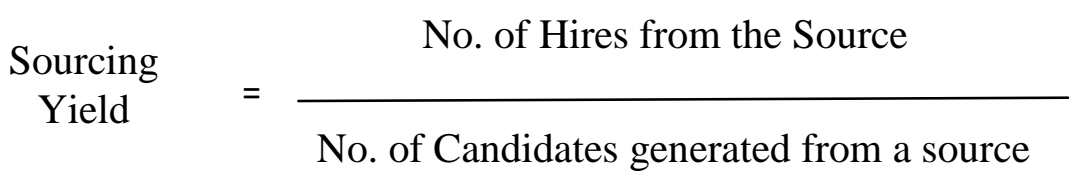

The technique adopted here is a "Simple Percentage Method". It refers to where the values are converted into percentage (taking a part in100 percentage) for better understanding of the collected data. It is used in analyzing many attitude questionnaires. It acts as a basis for predicting roughly what percentage of individuals in a second sample might express a particular attitude.

Points to note:

- Cost of the source

- Volume of candidates

- Future Trends

- Time of reach 
Table 6: Candidates profiling

\begin{tabular}{|l|l|l|l|l|l|l|l|l|l|l|l|l|l|}
\hline $\begin{array}{l}\text { Requirements/ } \\
\text { Details }\end{array}$ & $\begin{array}{l}\text { Total } \\
\text { Sourced }\end{array}$ & $\begin{array}{l}\text { Not } \\
\text { Shared }\end{array}$ & Shared & $\begin{array}{l}\text { Screen } \\
\text { Reject }\end{array}$ & $\begin{array}{l}\text { Inter- } \\
\text { Viewed }\end{array}$ & L1 & S & R & NR & L2 S & R & NI \\
\hline $\begin{array}{l}\text { GSM/GSM } \\
\text { Testing }\end{array}$ & 47 & 15 & 32 & 12 & 20 & 20 & 8 & 10 & 2 & 8 & 5 & 2 & 1 \\
\hline Java Testing & 11 & 3 & 8 & 3 & 5 & 5 & 3 & 2 & 0 & 3 & 2 & 1 & 0 \\
\hline $\begin{array}{l}\text { Protocol } \\
\text { Testing }\end{array}$ & 274 & 192 & 82 & 37 & 45 & 45 & 15 & 25 & 5 & 15 & 6 & 6 & 3 \\
\hline Java/J2EEE & 30 & 20 & 10 & 0 & 10 & NA & NA & NA & NA & 10 & 4 & 4 & 2 \\
\hline $\begin{array}{l}\text { N/W } \\
\text { Development }\end{array}$ & 336 & 110 & 226 & 176 & 50 & 50 & 26 & 21 & 3 & 26 & 11 & 12 & 3 \\
\hline C++,Linux & 150 & 90 & 60 & 22 & 38 & 38 & 16 & 19 & 4 & 16 & 7 & 6 & 3 \\
\hline FT & 100 & 42 & 58 & 32 & 26 & 26 & 8 & 15 & 3 & 8 & 6 & 1 & 1 \\
\hline N/W Testing & 141 & 90 & 51 & 13 & 38 & 38 & 13 & 22 & 3 & 13 & 6 & 5 & 2 \\
\hline ENS/NMS & 25 & 0 & 25 & 6 & 19 & 19 & 10 & 7 & 2 & 10 & 5 & 4 & 1 \\
\hline EPC & 10 & NA & 10 & 1 & 9 & 9 & 5 & 4 & 0 & 5 & 3 & 2 & 0 \\
\hline N/W Testing & 40 & 10 & 30 & 14 & 16 & 16 & 7 & 8 & 1 & 7 & 4 & 2 & 1 \\
\hline BO/BT/Wifi & 50 & 28 & 22 & 9 & 13 & 13 & 9 & 4 & 0 & 9 & 5 & 4 & 0 \\
\hline LTE & 15 & NA & 15 & 3 & 12 & 12 & 9 & 3 & 0 & 9 & 4 & 4 & 1 \\
\hline $\begin{array}{l}\text { EnodeB } \\
\text { Testing }\end{array}$ & 75 & 45 & 30 & 12 & 18 & 18 & 8 & 8 & 2 & 8 & 3 & 4 & 1 \\
\hline
\end{tabular}

\section{L1-Level 1}

After screening the candidates, recruiters has to schedule the first level interview which has telephonic with the availability of candidate and interviewer.

\section{S-Selected}

Candidate selected in first level interview

\section{$\underline{\text { R-Rejected }}$}

Those candidates who are not selected in first level.

\section{NR-Not Ready To Relocate}

If the requirement is in Bangalore and the candidates from another place, then he is not ready to relocate to Bangalore.

\section{L2-Level 2}

After candidate selected in first level interview recruiter has to schedule for the second level which is web discussion in Google hangouts.

\section{NI-Not Interested}

At the flow of the recruitment process many candidates are not interested.

In the first cluster GSM(Global System For Mobile) Testing, the recruiters source 47 resumes and after scrutinizing as per the job description, the recruiters shortlisted 32 resumes which were shared with the technical team.

The technical team again screen the resumes and further shortlisted 20 resumes for the interview. The recruiter scheduled the interview as per the convenience of the interviewers and interviewees. 8 members of 20 candidates cleared the $1^{\text {st }}$ round of interview (telephonic) excluding 2 candidates who were not ready for relocation.

Next level of interview is web discussion/ $\mathrm{f} 2 \mathrm{f}$. The candidates from the same place was asked to appear for $\mathrm{f} 2 \mathrm{f}$ interview and other were examined though web. 5 candidates got selected. 1 candidate was not interested. The process could follow for the other clusters too. 
Table 7: Profiling Ratio

\begin{tabular}{|l|l|l|l|l|l|}
\hline $\begin{array}{l}\text { Requirements/ } \\
\text { Details }\end{array}$ & Shared & Screened & LI(Select) & L2(Select) & Offered \\
\hline $\begin{array}{l}\text { GSM/GSM } \\
\text { Testing }\end{array}$ & $47: 32$ & $32: 20$ & $20: 8$ & $8: 5$ & $5: 4$ \\
\hline Java Testing & $11: 8$ & $8: 5$ & $5: 3$ & $3: 2$ & $2: 2$ \\
\hline $\begin{array}{l}\text { Protocol } \\
\text { Testing }\end{array}$ & $274: 82$ & $82: 45$ & $45: 15$ & $15: 6$ & $6: 4$ \\
\hline Java/J2EEE & $30: 10$ & $10: 10$ & NA & $10: 4$ & $4: 4$ \\
\hline $\begin{array}{l}\text { N/W } \\
\text { Development }\end{array}$ & $336: 226$ & $226: 50$ & $50: 26$ & $26: 11$ & $11: 9$ \\
\hline C++,Linux & $150: 60$ & $60: 38$ & $38: 16$ & $16: 7$ & $7: 5$ \\
\hline FT & $100: 58$ & $58: 26$ & $26: 8$ & $8: 16$ & $6: 3$ \\
\hline N/W Testing & $141: 51$ & $51: 38$ & $38: 13$ & $13: 6$ & $6: 5$ \\
\hline ENS/NMS & $25: 25$ & $25: 19$ & $19: 10$ & $10: 5$ & $5: 4$ \\
\hline EPC & $10: 10$ & $10: 9$ & $9: 5$ & $5: 3$ & $3: 3$ \\
\hline N/W Testing & $30: 20$ & $20: 16$ & $16: 7$ & $7: 4$ & $4: 3$ \\
\hline BO/BT/Wifi & $30: 22$ & $22: 13$ & $13: 9$ & $9: 5$ & $5: 4$ \\
\hline LTE & $15: 15$ & $15: 12$ & $12: 9$ & $9: 4$ & $4: 4$ \\
\hline EnodeB Testing & $75: 30$ & $30: 18$ & $18: 8$ & $8: 3$ & $3: 3$ \\
\hline
\end{tabular}

In table 6, we discuss in numeric values which shows different columns for the screening, selected, rejected. In this table 7 , we discuss the ratio of the numerical value for further clarity of profiling. In cluster 1 the GSM requirement shows the 47:32 shared which means the recruiter sources 47 profiles and after they matches the job description they shared 32 profiles to the technical team.

Screened 32:20, it means in the 32 profiles they screened the 20 profiles for the interview. Level 1, 20:8 it means 20 candidates attend the interview and in that 8 candidates selected for the second level interview.

Level 2, 8:5 it means 8 candidates are attended for the second level interview in that 5 candidates are selected.

Offered 5:4 it means, in 5 candidates the company offered only 4 candidates.

In this the recruitment process.

Similar process was followed for all the clusters.

Table 8: success yield percentage at each stage

\begin{tabular}{|l|l|l|l|l|l|}
\hline $\begin{array}{l}\text { Requirements/ } \\
\text { Details }\end{array}$ & Shared (\%) & Screened (\%) & Level1 (\%) & Level2 (\%) & Offered (\%) \\
\hline $\begin{array}{l}\text { GSM/GSM } \\
\text { Testing }\end{array}$ & 68 & 62 & 40 & 62 & 80 \\
\hline Java Testing & 73 & 62 & 60 & 67 & 100 \\
\hline $\begin{array}{l}\text { Protocol } \\
\text { Testing }\end{array}$ & 30 & 55 & 33 & 40 & 67 \\
\hline Java/J2EE & 33 & 100 & NA & 40 & 100 \\
\hline $\begin{array}{l}\text { N/W } \\
\text { Development }\end{array}$ & 67 & 22 & 52 & 42 & 82 \\
\hline C++, Linux & 40 & 63 & 42 & 44 & 71 \\
\hline FT & 58 & 45 & 31 & 75 & 71 \\
\hline N/W Testing & 36 & 74 & 34 & 46 & 83 \\
\hline ENS/NMS & 100 & 76 & 53 & 50 & 80 \\
\hline EPC & 100 & 90 & 55 & 60 & 100 \\
\hline N/W Testing & 67 & 80 & 44 & 58 & 75 \\
\hline
\end{tabular}




\begin{tabular}{|l|l|l|l|l|l|}
\hline BO/BT/Wifi & 73 & 59 & 69 & 55 & 80 \\
\hline LTE & 100 & 80 & 75 & 44 & 100 \\
\hline $\begin{array}{l}\text { EnodeB } \\
\text { Testing }\end{array}$ & 40 & 60 & 44 & 37 & 100 \\
\hline
\end{tabular}

In table 8 , we discussed the data in percentage which are presented as follows:

In Screened 32:20 ratio the percentage is 62 .

In Level 1 20:8 ratio the percentage is 40 .

In level $28: 5$ ratio the percentage is 62 .

In offered 5:4 ratio the percentage is 80 .

Similar process follows for all the clusters.

Table 9: No. of candidates for not showing interest

\begin{tabular}{|c|c|c|c|c|c|c|c|}
\hline \multirow{2}{*}{$\begin{array}{l}\text { Requirements/ } \\
\text { Details } \\
\text { Code }\end{array}$} & \multicolumn{2}{|c|}{ Not Shared } & \multirow[b]{2}{*}{ NIB } & \multirow[b]{2}{*}{$\begin{array}{l}\text { PNM/ } \\
\text { IPNM }\end{array}$} & \multirow{2}{*}{$\begin{array}{l}\begin{array}{l}\text { Screen } \\
\text { Reject }\end{array} \\
\text { SR }\end{array}$} & \multirow{2}{*}{$\begin{array}{l}\text { Level } 1 \\
\text { NIC/N }\end{array}$} & \multirow{2}{*}{$\begin{array}{l}\text { Level } 2 \\
\text { NIT/NI }\end{array}$} \\
\hline & HP & $\begin{array}{l}\text { NI/NIR/ } \\
\text { NIP }\end{array}$ & & & & & \\
\hline GSM/GSM Testing & 6 & 3 & 2 & 4 & 12 & 2 & 1 \\
\hline Java Testing & 1 & 1 & 0 & 1 & 3 & 0 & 0 \\
\hline Protocol Testing & 42 & 50 & 30 & 70 & 37 & 5 & 3 \\
\hline Java/J2EE & 5 & 5 & 5 & 5 & 0 & NA & 2 \\
\hline N/W Development & 27 & 16 & 51 & 16 & 176 & 3 & 3 \\
\hline $\mathrm{C}++$, Linux & 20 & 25 & 25 & 15 & 22 & 4 & 3 \\
\hline FT & 10 & 12 & 10 & 10 & 32 & 3 & 1 \\
\hline N/W Testing & 15 & 20 & 25 & 25 & 13 & 3 & 2 \\
\hline ENS/NMS & 0 & 0 & 0 & 0 & 6 & 2 & 1 \\
\hline EPC & $\mathrm{NA}$ & NA & $\mathrm{NA}$ & NA & 1 & 0 & 0 \\
\hline N/W Testing & 1 & 2 & 2 & 5 & 14 & 1 & 1 \\
\hline BO/BT/Wifi & 7 & 6 & 7 & 8 & 9 & 0 & 0 \\
\hline LTE & $\mathrm{NA}$ & NA & NA & NA & 3 & 0 & 1 \\
\hline EnodeB Testing & 3 & 1 & 1 & 0 & 12 & 2 & 1 \\
\hline
\end{tabular}

The table shows the range of unattached candidates for various reasons:

- HP - High Package

- NI/NIC/NIR - Not interested, not responding to calls, not looking for change/ not interested in profile

- C - From client

- NIB - Location barrier

- PNM/IPNM - Profile not matching, interested profile not matching

- SR- Screen Reject

- NIT - Candidate did not turn out

In table 9, we discuss the reasons behind poor attraction of the candidates towards the job.

Not Shared-In this table and also in each cluster, many candidates are not interested for the job. In first cluster for GSM Testing, 6 candidates are looking for High Price and 3 candidates are not interested to relocate or not Interested to reprofile and not Interested in Bangalore. Some 
candidates profiles are not matching and there are some profiles that are matching, but candidates are not showing interests.

Screen Reject- The technical team also have some reasons to reject the candidates profiles.

Level 1 - in level 1 , some candidates are not responding the calls the interviewers calls for the telephonic interview.

Level 2- in level 2, some candidates dropped their interest to further their candidature and left.

Figure 1: Reasons of poor attraction in each cluster

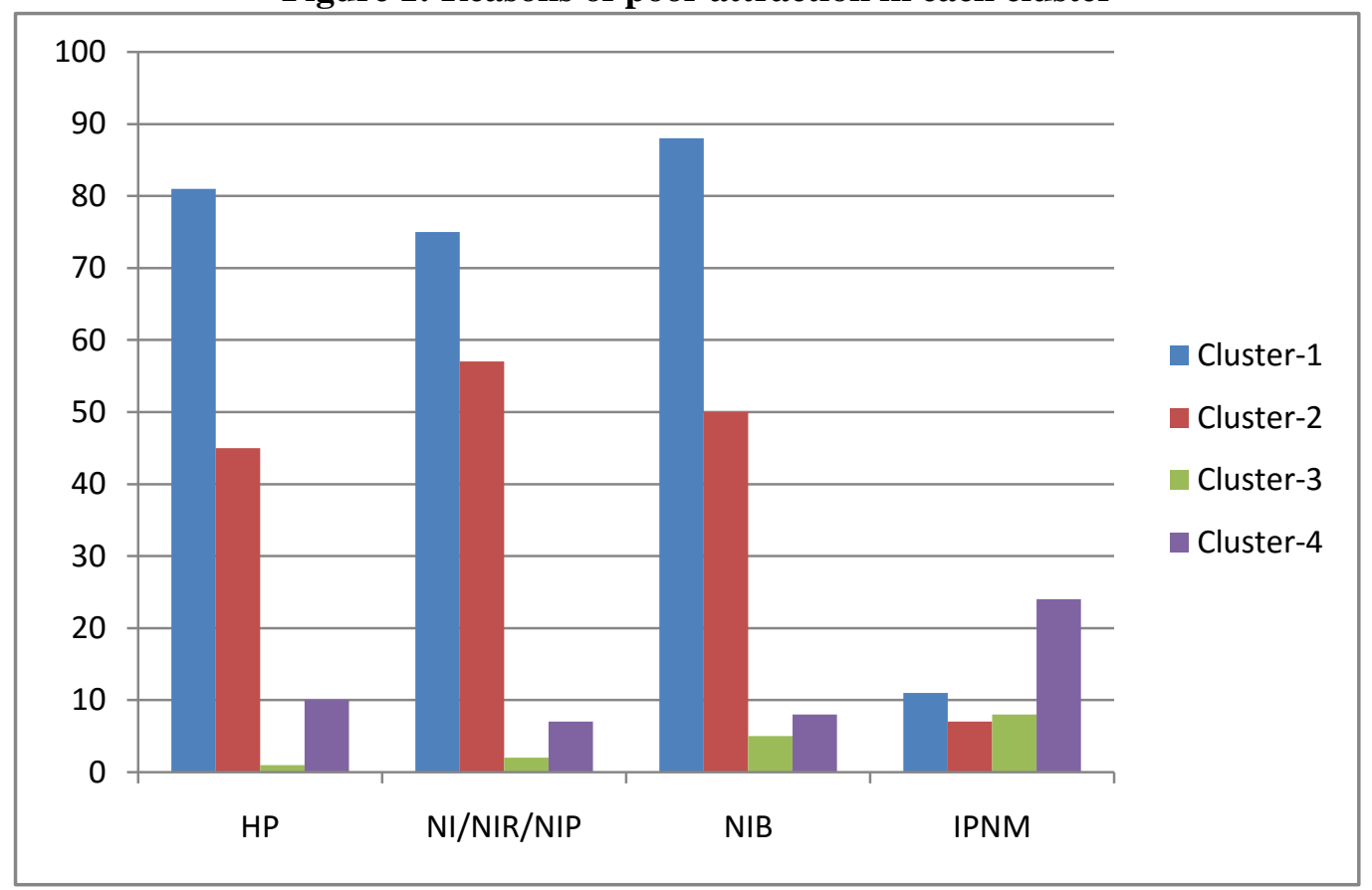

In the above graph, we discuss the candidate's poor attraction in this bar-graph. The blue color refers to the cluster 1, high price candidates are $80 \%$ and Not Interested are $75 \%$, and Not interested in Bangalore are 85\% and Interested profile not matching are 10\%. Likewise, the process could follow for rest of the cluster.

Table 10: Source yield in cluster 1

\begin{tabular}{|c|c|c|c|}
\hline Cluster-1 & Generated & Screened & Selected \\
\hline Naukri & 579 & 100 & 23 \\
\hline Buddy Referral & 70 & 12 & 3 \\
\hline Linkedin & 7 & 1 & 0 \\
\hline Vendors & 42 & 7 & 2 \\
\hline Monster & 0 & 0 & 0 \\
\hline
\end{tabular}

The above table shows where the recruiters source the candidates and how much they get the results. In this cluster the profiles are sourced from the Naukri, Buddy and LinkedIn, Vendor and they give very less priority to the Monster. From the Naukri the profiles are generated and screened the profiles and within them they selected the profiles. 
Figure 2: Source yield in cluster 1

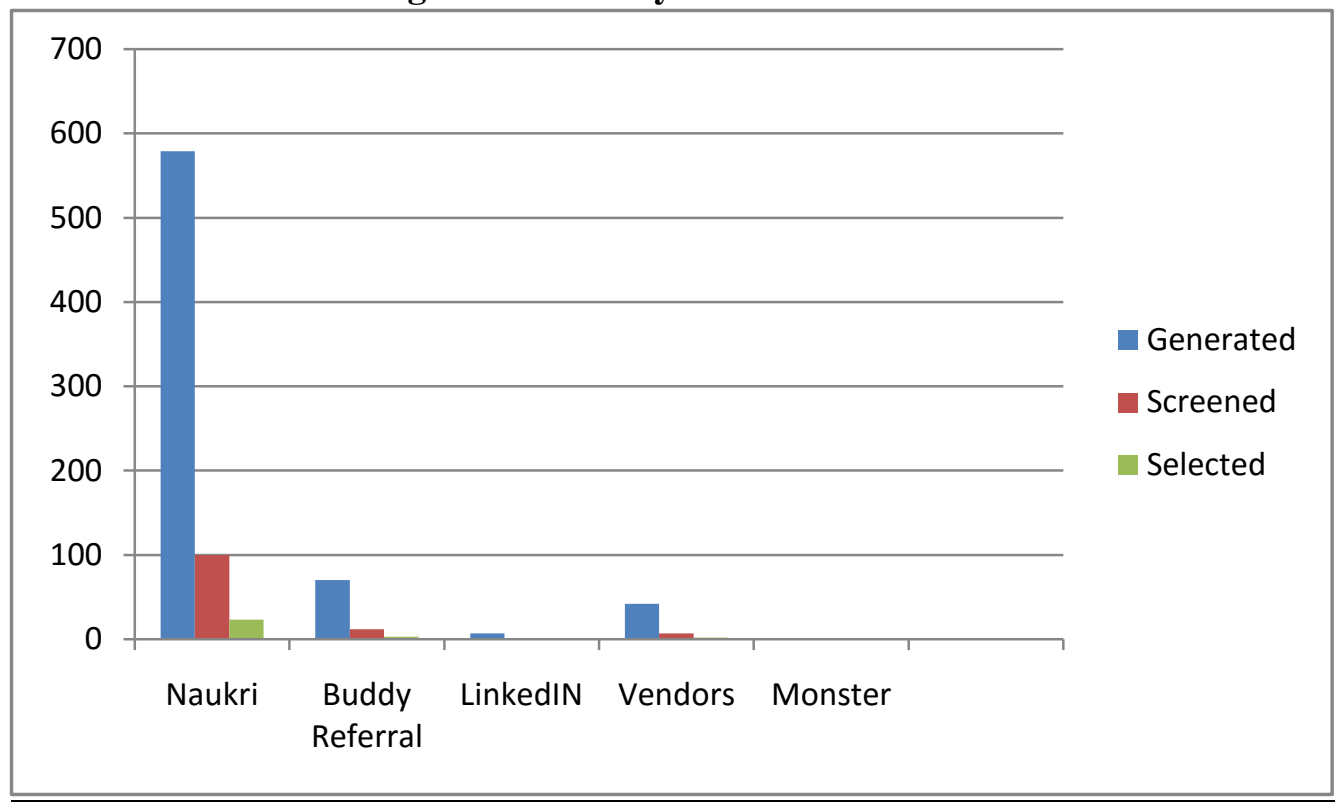

The graph 2 shows that 586 candidates are sourced from Naukri and 70 from buddy referral, 7 from LinkedIn, 42 from vendors and zero from the monster. Out of the total sourced candidatures, 12 are screened from buddy and 1 from LinkedIn and 7 from vendors.

From, 7 are selected from Naukri, 3 from buddy referral, 2 from vendor and zero from LinkedIn.

Table 12: Source yield in cluster 2

\begin{tabular}{|c|c|c|c|}
\hline Cluster-2 & Generated & Screened & Selected \\
\hline Naukri & 324 & 85 & 16 \\
\hline Buddy Referral & 35 & 9 & 2 \\
\hline Linkedin & 0 & 0 & 0 \\
\hline Vendors & 27 & 7 & 1 \\
\hline Monster & 5 & 1 & 0 \\
\hline
\end{tabular}

The table 12 presents the source yield in cluster 2. In this cluster, the profiles are sourced from the Naukri, Buddy and LinkedIn, Vendor and Monster. The profiles are generated from the job sites, screened and selected.

Figure 3: Source Yield in Cluster 2 
Figure 3: Source yield in cluster 2

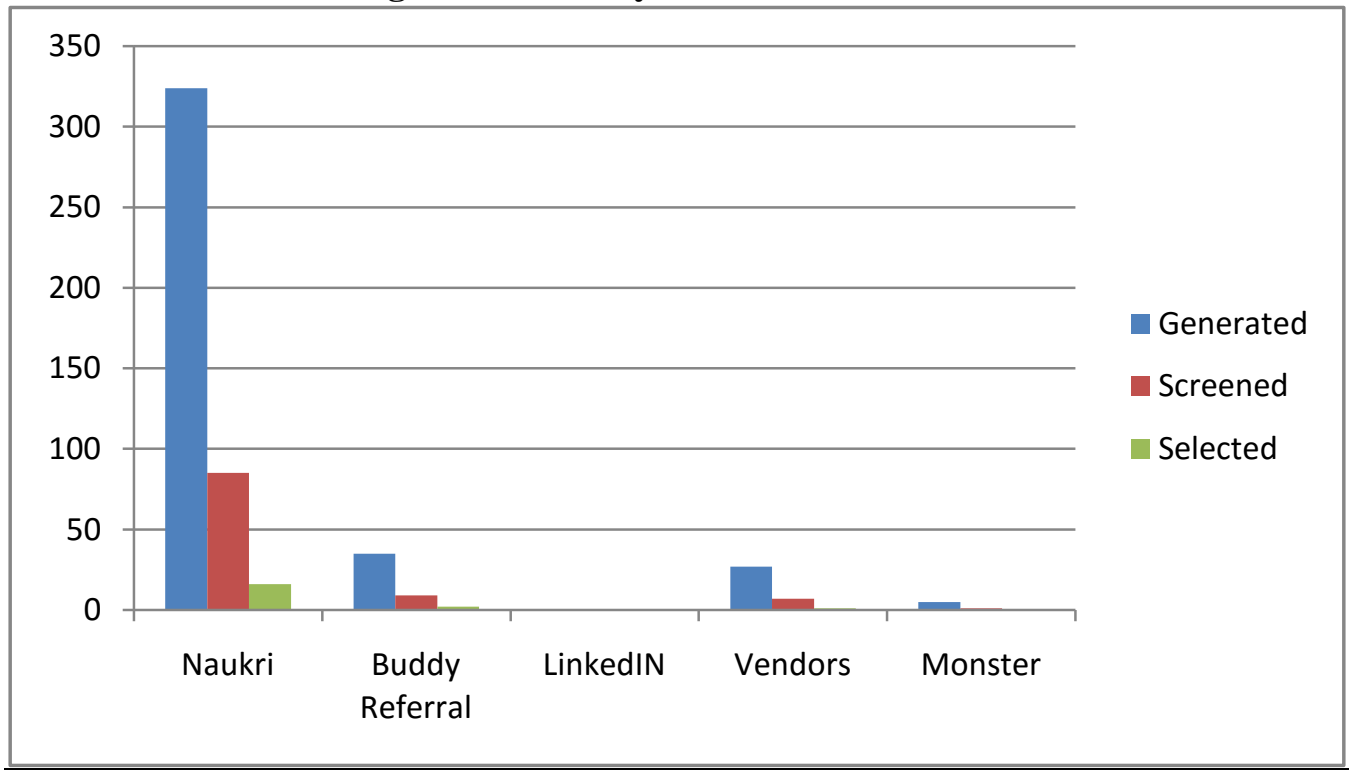

The graph shows that 324 candidates are sourced from Naukri, 35 from buddy referral, 0 from LinkedIn, 27 from Vendors and 5 from the monster. Out of all those, 85 are screened from buddy 9 , zero from LinkedIn, 7 from vendors and 1 from monster. 16 are selected from Naukri, 2 from Buddy Referral, 1 from vendors, none from monster and linkedin.

Table 13: Source yield in cluster 3

\begin{tabular}{|c|c|c|c|}
\hline Cluster-3 & Generated & Screened & Selected \\
\hline Naukri & 60 & 35 & 10 \\
\hline Buddy Referral & 0 & 0 & 0 \\
\hline Linkedin & 0 & 0 & 0 \\
\hline Vendors & 15 & 9 & 2 \\
\hline Monster & 60 & 35 & 10 \\
\hline
\end{tabular}

The table shows source yield in cluster 3. In this cluster, the profiles are sourced from the Naukri, Buddy and LinkedIn, Vendor and Monster. The profiles are generated from the job sites, screened and selected too.

Figure 4: Source yield in cluster 3

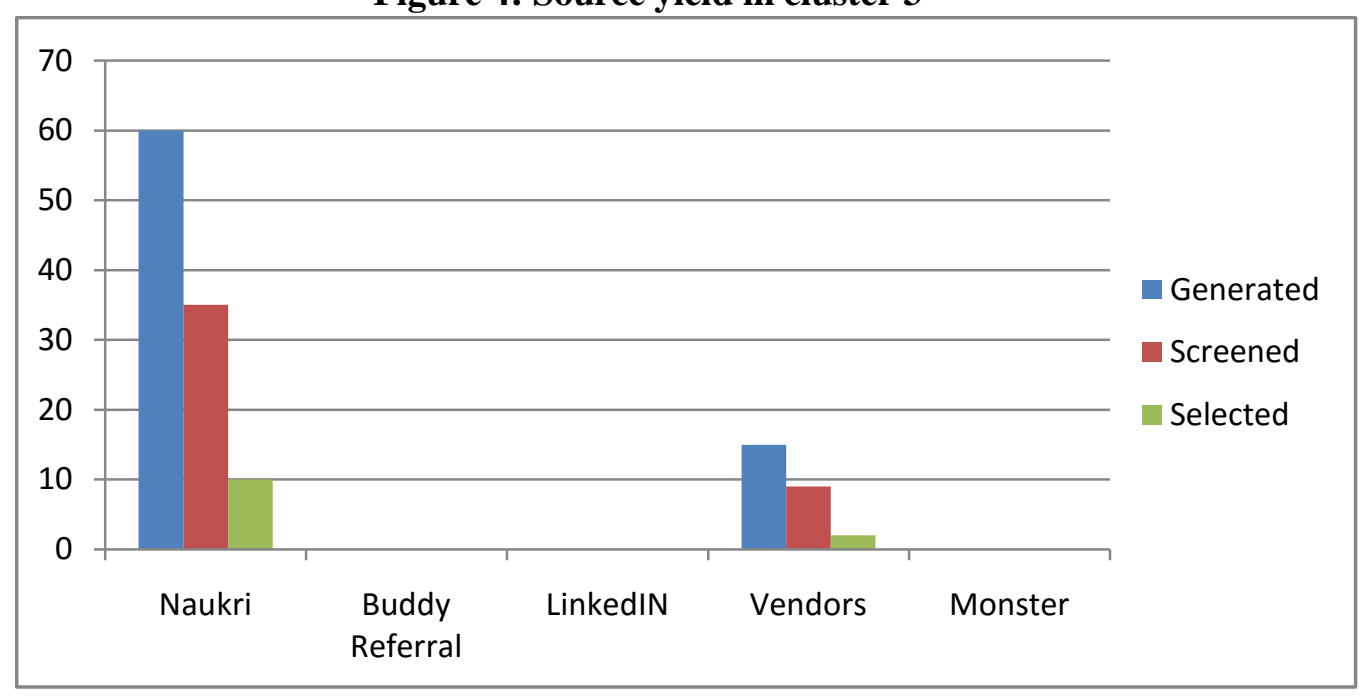


The graph and table show that 60 from Naukri are sourced, zero from buddy referral, zero from LinkedIn, 15 from vendors, zero from monster. In that 35 are screened and for buddy 0 and in LinkedIn only 0 and from vendors 9 are screened and none from monster.

From Naukri, 10 are selected and 10 from buddy referral and none from LinkedIn and 9 from vendors.

Table 14: Source yield in cluster 4

\begin{tabular}{|l|c|c|c|}
\hline Cluster-4 & Generated & Screened & Selected \\
\hline Naukri & 112 & 34 & 10 \\
\hline Buddy Referral & 21 & 7 & 2 \\
\hline LinkedIn & 7 & 2 & 0 \\
\hline
\end{tabular}

The table 14 presents the source yield in Cluster 4. In this cluster, the profiles are also sourced from Naukri, Buddy, LinkedIn and none from Vendor and Monster. From the Naukri, most of the profiles are generated, screened and selected.

Figure 5: Source yield in cluster 4

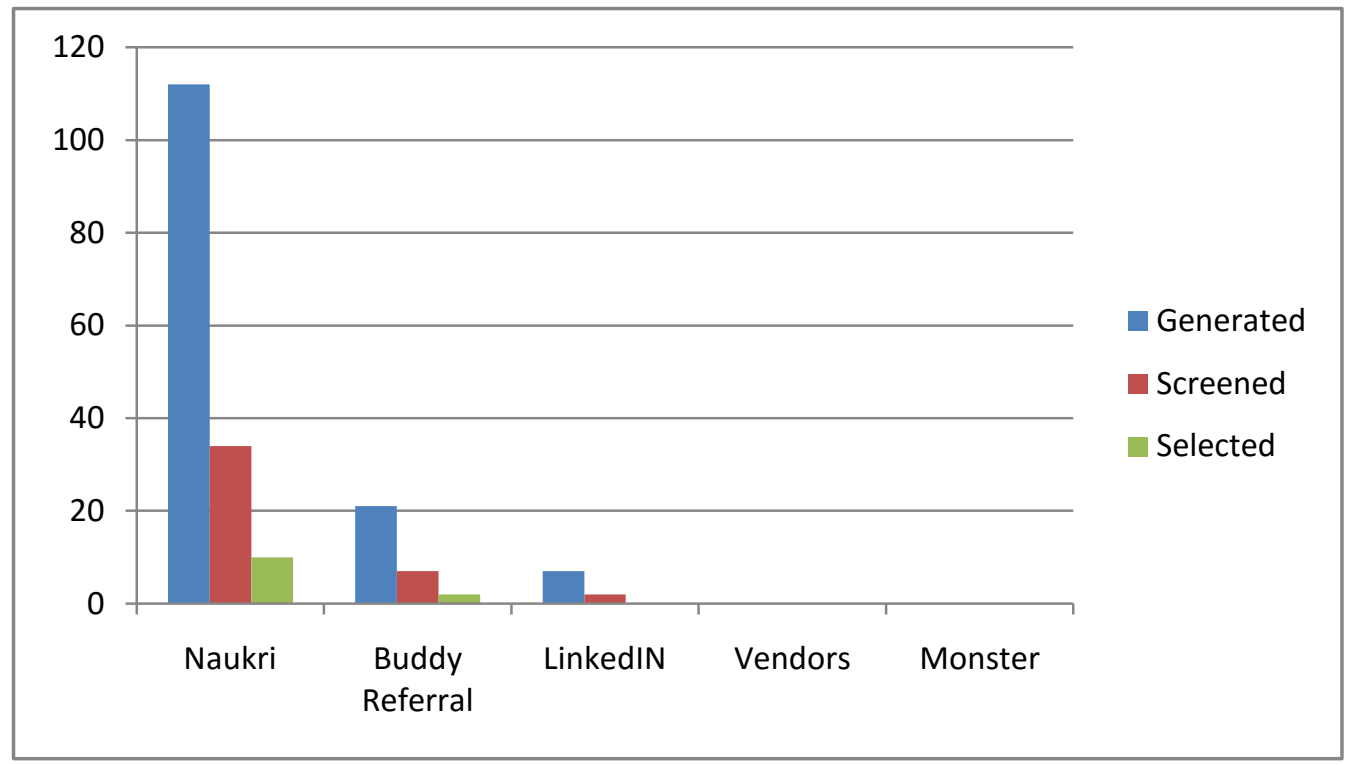

The graph shows the 112 from Naukri are sourced, 21 from buddy referral 7 from LinkedIn and none from vendors. 34 are screened from Naukri, 7 from buddy, 2 from and 2 from LinkedIn. From Naukri, 10 are selected and 2 from buddy referral and none LinkedIn

\subsection{Problems encountered by the Recruiters}

Recruiter faces many difficulties to create interest in the candidates for the requirement. Many times, the candidates agree to appear for the interview, but do not appear. The recruiters have to rediscuss and reschedule the interview which also does not guarantee that the candidates will turn up. It is significant to maintain the tracker to monitor candidates profiling in the recruitment process. Recruiter has to undertake responsibility to maintain tracker and updated to the senior HR even if the flow of candidates is highly volatile at each stage of recruitment. Sometimes clients want some urgent requirement, in that case they arranging the weekend drives to recruit the maximum candidates.

\subsection{Tracker Details}

Trackers are used to handle all the information of the candidates who are offered the jobs. It helps the company in tracking the performance of the employees till they join the organization. 
It contains details on package offered, deviations (if any), and Location details. The below is the contribution from each source in last four years on all verticals \& horizontals.

Table 15: The Tracker Details

\begin{tabular}{|l|l|l|l|l|l|l|}
\hline Status & Naukri & Buddy & Vendor & Monster & Linkedin & Total \\
\hline Selected & 59 & 7 & 5 & 0 & $\mathbf{0}$ & 71 \\
\hline Offered & 48 & 5 & 3 & 0 & $\mathbf{0}$ & 56 \\
\hline Declined & 15 & 2 & 1 & 0 & $\mathbf{0}$ & 18 \\
\hline Joined & 32 & 2 & 2 & 0 & 0 & 36 \\
\hline To Join & 1 & 1 & 0 & 0 & 0 & 2 \\
\hline
\end{tabular}

\subsection{Conclusion}

HR program audit is a part of every HR activity of the company. The HR Auditor is satisfied with the standard procedure being followed in compliance to the company HR policy of the company with a view to selecting the best person for the job. Evidence of this includes the development of relevant job descriptions, structured assessment mechanisms and training for interview board members, all underpinned by appropriate documented management systems. Nevertheless, the auditor has identified areas for further improvement which are presented below:

- That management systems should be reviewed to ensure that fully documented records, including all original supporting documentation, are retained to clearly support each stage of the process.

- That effective systems are in place to manage the feedback function and this information is communicated to candidates at the outset of the process.

\section{Reference}

- Sahoo D.K \& Sahoo C.K (2011). "Human Resource Management in New Global Era", $1^{\text {st }}$ ed. Enkey Publishing House, New Delhi.

- Sahoo D.K \& Sahoo C.K (2011). "Modern Human Resource Management", $1^{\text {st }}$ ed. Enkey Publishing House, New Delhi. 